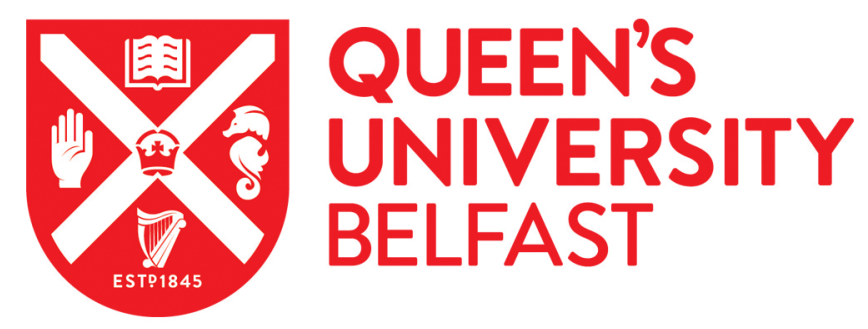

\title{
Mechanical properties of $\alpha$-tricalcium phosphate-based bone cements incorporating regenerative biomaterials for filling bone defects exposed to low mechanical loads
}

Harrison, R., Criss, Z. K., Feller, L., Modi, S. P., Hardy, J. G., Schmidt, C. E., Suggs, L. J., \& Murphy, M. B. (2016). Mechanical properties of a-tricalcium phosphate-based bone cements incorporating regenerative biomaterials for filling bone defects exposed to low mechanical loads. Journal of Biomedical Materials Research - Part B: Applied Biomaterials, 104(1), 149-157. https://doi.org/10.1002/jbm.b.33362

Published in:

Journal of Biomedical Materials Research - Part B: Applied Biomaterials

Document Version:

Early version, also known as pre-print

Queen's University Belfast - Research Portal:

Link to publication record in Queen's University Belfast Research Portal

\begin{abstract}
Publisher rights
(C) 2015 Wiley Periodicals, Inc.

This is the pre-peer reviewed version of the following article: Harrison R, Criss ZK, Feller L, Modi SP, Hardy JG, Schmidt CE, Suggs LJ, Murphy MB. 2015. Mechanical properties of a-tricalcium phosphate-based bone cements incorporating regenerative biomaterials for filling bone defects exposed to low mechanical loads. J Biomed Mater Res Part B 2015:00B:000-000, which has been published in final form at http://onlinelibrary.wiley.com/doi/10.1002/jbm.b.33362/full.

General rights

Copyright for the publications made accessible via the Queen's University Belfast Research Portal is retained by the author(s) and / or other copyright owners and it is a condition of accessing these publications that users recognise and abide by the legal requirements associated with these rights.
\end{abstract}

Take down policy

The Research Portal is Queen's institutional repository that provides access to Queen's research output. Every effort has been made to ensure that content in the Research Portal does not infringe any person's rights, or applicable UK laws. If you discover content in the Research Portal that you believe breaches copyright or violates any law, please contact openaccess@qub.ac.uk. 


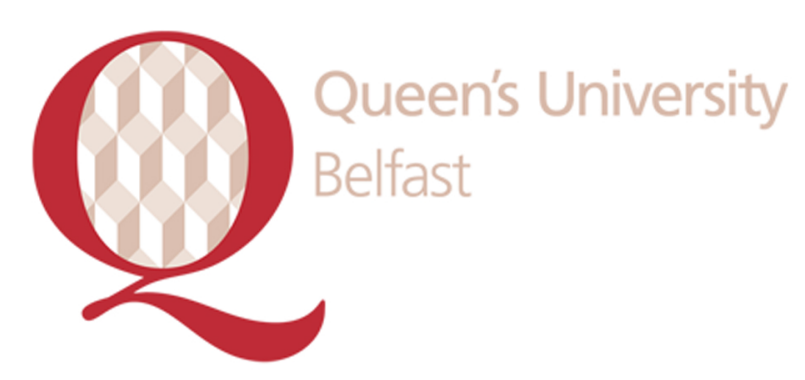

\section{Queen's University Belfast - Research Portal}

\section{Mechanical properties of -tricalcium phosphate-based bone cements incorporating regenerative biomaterials for filling bone defects exposed to low mechanical loads}

Harrison, R., Criss, Z., Feller, L., Modi, S., Hardy, J. G., Schmidt, C. E., ... Murphy, M. (2015). Mechanical properties of -tricalcium phosphate-based bone cements incorporating regenerative biomaterials for filling bone defects exposed to low mechanical loads. Journal of Biomedical Materials Research - Part B: Applied Biomaterials.

Published in:

Journal of Biomedical Materials Research - Part B: Applied Biomaterials

Link:

Link to publication record in Queen's University Belfast Research Portal

\footnotetext{
Publisher rights

The version posted must acknowledge acceptance for publication and, following publication of the final paper, contain the text: "This is the pre-peer reviewed version of the following article: [FULL CITE], which has been published in final form at [Link to final article].

\section{General rights}

Copyright for the publications made accessible via the Queens University Belfast Research Portal is retained by the author(s) and / or other copyright owners and it is a condition of accessing these publications that users recognise and abide by the legal requirements associated with these rights.

Take down policy

The Research Portal is Queens institutional repository that provides access to Queens research output. Every effort has been made to ensure that content in the Research Portal does not infringe any persons rights, or applicable UK laws. If you discover content in the Research Portal that you believe breaches copyright or violates any law, please contact openaccess@qub.ac.uk.
} 
Full title of the paper: Mechanical properties of $\alpha$-tricalcium phosphate-based bone cements incorporating regenerative biomaterials for filling bone defects exposed to low mechanical loads.

Authors full names: Reed Harrison, ${ }^{1}$ Zachary K. Criss, ${ }^{1 \dagger}$ Lacie Feller, ${ }^{1 \dagger}$ Shan P. Modi, ${ }^{1 \dagger}$ John

G. Hardy, ${ }^{1,2 *}$ Christine E. Schmidt, ${ }^{1,2 *}$ Laura J. Suggs ${ }^{1 *}$ and Matthew B. Murphy ${ }^{1 *}$

$\dagger$ Authors contributed equally.

* Authors to whom correspondence should be addressed.

\section{Authors addresses:}

1) Department of Biomedical Engineering, The University of Texas at Austin, Austin, TX 78712.

2) J. Crayton Pruitt Family Department of Biomedical Engineering, University of Florida, Biomedical Sciences Building JG-53, P.O. Box 116131, Gainesville, FL 32611-6131.

E-mail (JGH): johnhardyuk@gmail.com

E-mail (CES): schmidt@bme.ufl.edu

E-mail (LJS): laura.suggs@mail.utexas.edu

E-mail (MBM): mbmurphy@utexas.edu 


\begin{abstract}
Calcium phosphate-based cements with enhanced regenerative potential are promising biomaterials for the healing of bone defects. With a view to the use of such cements for low load bearing applications such as sinus augmentation or filling extraction sites, we have prepared $\alpha$ tricalcium phosphate ( $\alpha$-TCP)-based bone cements including materials that we would expect to improve their regenerative potential, and describe the mechanical properities of the resulting formulations herein. Formulations incorporated $\alpha$-TCP, hydroxyapatite, biopolymer-thickened wetting agents, sutures, and platelet poor plasma. The mechanical properties of the composites were composition dependent, and optimized formulations had clinically relevant mechanical properties. Such calcium phosphate-based cements have potential as replacements for cements such as those based on polymethylmethacrylate (PMMA).
\end{abstract}

Key Words: biodegradable, biomaterials, composites, mineral

Running Head: Bone cements based on $\alpha$-tricalcium phosphate and biopolymers 


\section{INTRODUCTION}

The development of implantable biodegradable materials is of great importance for regenerative medical technologies (i.e., drug delivery devices and tissue scaffolds) ${ }^{1-4}$ Biomaterials capable of conforming to patient-specific cavities are particularly desirable and have broad applicability in vivo for tissues with a variety of different mechanical properties. ${ }^{1-4}$ For example, hydrogels with low compressive moduli are useful for central and peripheral nervous tissue engineering, whereas cements with relatively high compressive moduli are applicable to bone tissue engineering. ${ }^{1-4}$ Consequently, moldable biomaterials such as these have the potential to be offthe-shelf personalized medical treatments that can adapt to fill arbitrary three-dimensional shapes by adapting to conform to cavities within specific patients. ${ }^{1-4}$

Bones are hierarchically structured composite materials ${ }^{5}$ that are predominantly composed of collagen and hydroxyapatite (a form of calcium phosphate), and this hard mineral protects softer vascularized cell-rich tissue that is embedded within the bone. There is great demand for biomaterials for the repair of bone defects, with more than 500,000 patients treated annually in the United States alone, and the market for such products is worth more than $\$ 2.5$ billion. ${ }^{6}$ Consequently, a variety of materials for bone tissue engineering have been developed, of which, calcium phosphate-based cements are one class., 3, 7-16Ideally, the mechanical properties (modulus and strength) for materials intended to replace/repair bone should mimic those of the natural bone. For low load bearing applications such as sinus augmentation or filling extraction sites, the strength is of minimal importance, and the Young's modulus should be ca. 0.051GPa. ${ }^{17}$ For medium load bearing applications such as alveolar cleft repairs, alveolar ridge augmentations and calvarian repairs, the strength would ideally be above $50 \mathrm{MPa}$ and the 
modulus ca. $1 \mathrm{GPa}$; whereas for high load bearing applications such as segmental mandibular/tibial defect repair or cervical disk repair, the strength should be greater than 150 MPa and the modulus ca. 10-30 GPa. ${ }^{17}$ Calcium phosphate-based cements are one class of materials under investigation for such applications because of their ease of formulation and application. $^{18,19}$

While there are a variety of PMMA-based and calcium phosphate based cements available, PMMA-based cements are known to trigger apoptosis in the tissue surrounding the site of application because the setting process is exothermic. ${ }^{20,21}$ Furthermore, PMMA-based cements are not biodegradable, and consequently cannot be remodeled in vivo to form a fully integrated section of functional bone tissue. Calcium phosphate-based cements ${ }^{22-29}$ represent an attractive alternative to PMMA-based cements ${ }^{20,21}$ because they can be remodeled, integrate well with bone, and generate little heat in setting. There are many formulations of calcium phosphate cements (CPC) reported in the literature, and appropriately designed formulations have compressive strengths and compressive moduli that can be used for low, medium or high loadbearing applications. ${ }^{18,19}$ The inclusion of fibers in CPC formulations is typically intended to reinforce the cement, but fibers that are too short can reduce the strength and modulus of these formulations by acting as a site from which crack propagation can occur. ${ }^{18,19}$ We sought to design a regenerative CPC formulation suitable for filling bone defects exposed to low compressive loads (e.g., sinus augmentation, filling extraction sites). ${ }^{17-19}$

In contrast to the CPC variants available, we investigated composites with the potential to impart long term macroporosity, incorporate healing cofactors from plasma, and expedite bone ingrowth/remodeling. ${ }^{28}$ To achieve these goals, we investigate CPC formulations based on $\alpha$ - 
tricalcium phosphate ( $\alpha$-TCP) and hydroxyapatite. Using these base components, we observe the mechanical effects of introducing biopolymer-thickened wetting agents, blood plasma wetting agents, and biodegradable polymer-based sutures (that in the long-term should degrade leaving pores to expedite bone ingrowth and remodeling). We report herein a variety of previously unreported low cost CPC formulations mechanical properties suitable for low load bearing applications.

\section{MATERIALS AND METHODS}

\section{Materials and Synthetic/Analytical Methods}

Unless otherwise stated, all chemicals were of ACS grade, purchased from Sigma-Aldrich and used as received without further purification. Oasis Monofyl ${ }^{\circledR}$ 4-0 biodegradable sutures (SouthPointe Surgical Supply, Inc., FL), and polyglycolic acid (PGA) 4-0 biodegradable sutures were purchased from (Suture Direct, IL). 4-0 sutures have diameters of $150 \mu \mathrm{m}$ and were cut to lengths of $5 \mathrm{~mm}$ with a razor blade. Platelet poor plasma (PPP) was isolated via centrifugation of human whole blood (South Texas Tissue Center, TX) at $2000 \mathrm{~g}$ for 5 minutes.

\section{Preparation of $\alpha$-TCP}

$\alpha$-TCP was prepared via the solid state reaction between calcium carbonate (1 molar equivalent) and dibasic calcium phosphate dihydrate (two molar equivalents) in accordance with the literature. ${ }^{30}$ Reagents were shaken at $10 \mathrm{~Hz}$ for 30 minutes using a Mixer Mill MM 300 (Retsch GmbH, Germany) with a stainless steel ball bearing grinding chamber using one stainless steel ball of 1" in diameter. The resulting powders were heated under vacuum at a rate of $1000{ }^{\circ} \mathrm{C} / \mathrm{hr}$, held at $1200{ }^{\circ} \mathrm{C}$ for 12 hours in a graphite-lined furnace (Furnace Source LLC, CT), and 
subsequently allowed to cool under vacuum in the furnace to $300{ }^{\circ} \mathrm{C}$ before opening the oven and allowing the material to cool to room temperature in air. The resulting solid was analyzed via Fourier Transform Infrared Spectroscopy (FTIR) and X-Ray Diffraction (XRD). The remainder of the $\alpha$-TCP was ground into a coarse powder using a mortar and pestle, prior to grinding for 30 minutes using a Mixer Mill MM 300 (Retsch GmbH, Germany) with a stainless steel ball bearing grinding chamber using one stainless ball of 1” in diameter and shaking at $10 \mathrm{~Hz}$, yielding a finely ground powder.

\section{Fourier Transform Infrared Spectroscopy (FTIR)}

Infrared spectroscopy was carried out on a JASCO FTIR 4100 Spectrometer (Thermo Fisher Scientific Inc., USA). Spectra were recorded for 128 scans at $21{ }^{\circ} \mathrm{C}$, with a $1 \mathrm{~cm}^{-1}$ resolution. Absorbance spectra of $\mathrm{KBr}$ discs were recorded in transmission mode, as were spectra of the pure solid powder in attenuated total reflectance (ATR) mode. Spectra were corrected for background and atmosphere using the software provided with the spectrometer.

\section{X-ray Diffraction (XRD)}

XRD data was collected on a Rigaku R-Axis Spider diffractometer with an image plate detector using a graphite monochromator with $\mathrm{CuK} \alpha$ radiation $(\lambda=1.5418 \AA)$ at room temperature. The instrument was controlled using Rapid/XRD diffractometer control software (Rapid/XRD Version 2.3.8., Rigaku Americas Corporation, The Woodlands, TX). The step size in $2 \Theta$ (degrees) was 0.01 , and the acquisition time per step was 0.2 seconds. The integration of the two dimensional data into a one dimensional pattern was accomplished using 2DP (2DP Version 1.0., 
Rigaku Americas Corporation, The Woodlands, TX). All XRD pattern analysis was performed using JADE software (MDI, v 8.1).

\section{Particle size analysis}

Milled powder was mounted on a Scanning Electron Microscopy (SEM) stub and sputter coated with Pt/Pd (15 nm). All powders were imaged using a Zeiss Supra 40 VP field emission scanning electron microscope. The ImageJ analyze particle command was used to calculate surface area of particles from each of four SEM images after first subtracting the background with a Gaussian blur filter, normalizing the contrast, applying a mean filter, and creating a binary image. Prism was used to re-express data as the $\log _{10}$ (particle size in $\mu \mathrm{m}^{2}$ ), to create a histogram of this data, and to fit a normal curve to the distribution data. Since the particle geometry is observed to be irregular, when reporting metrics relevant to the normal curve we converted data back to a nonlogarithmic scale and report surface area. To more easily conceptualize these values, we also report a particle diameter by assuming a circular geometry.

\section{CPC Preparation}

Cements were prepared by mixing wetting agents including biopolymer-based thickeners $34 \mathrm{wt}$ $\%$ (of various compositions, Table 1) and calcium phosphates 66 wt \% (typically composed from $\alpha$-TCP (98 wt \%) and hydroxyapatite (2 wt \%)), with the optional addition of biodegradable sutures (up to $1.5 \mathrm{wt} \%$ ). Wetting agents were composed of an aqueous solution of disodium phosphate (4 wt \%) to which was added various combinations of carboxymethyl cellulose sodium salt (CMC, MW $700 \mathrm{kDa}, 1 \mathrm{wt} \%$ in disodium phosphate solution, corrected to $\mathrm{pH} 7.4$ with $1 \mathrm{M} \mathrm{HCl}$ ) or bovine gelatin (1 wt \% in disodium phosphate solution) and platelet poor 
plasma (PPP). The precise compositions of each cement are presented in Table 1. Cements were mixed for at least 20 seconds in a glass Petri dish prior to packing into a BD syringe ( $3 \mathrm{~mL}$, ca. $8.3 \mathrm{~mm}$ internal diameter) with its tip removed which is analogous to the methodology used to prepare dental putty prior to packing them into patient-specific dental cavities. The syringes were rendered air-tight with a rubber stopper that prevented evaporation and incubated at $37^{\circ} \mathrm{C}$ for 24 hours to allow the cement to set. After 24 hours the cylinders were cut into segments of $12 \mathrm{~mm}$ in length for mechanical testing or $2.5 \mathrm{~mm}$ for in vitro degradation studies using a razor blade.

\section{Mechanical Testing}

The compressive moduli and strengths of the cement formulations were assessed using an Instron Materials Testing Machine 5543 (Instron, Norwood, MA). Compressive extension tests were performed at $21^{\circ} \mathrm{C}$ using a load cell weight of $5 \mathrm{kN}$ and a deformation rate of $0.05 \mathrm{~mm} \mathrm{~s}^{-1}$, slightly faster than similar studies to account for the larger load cell. ${ }^{31,32}$ Cylindrical testing specimens for compressive extension tests were $8.3 \mathrm{~mm}$ in diameter and $12 \mathrm{~mm}$ in height, which is within the range of comparable CPCs reported in the literature. ${ }^{31-33}$ Compressive moduli, compressive strengths, and moduli of resilience were determined and plotted using $\mathrm{R}$ (http://www.r-project.org/). Statistical analysis via ANOVA was also carried out within R: one way ANOVA statistics were calculated and interpreted with Tukey's multiple comparison test.

\section{In Vitro Degradation}

Precisely weighed sections of cements were incubated in phosphate-buffered saline (PBS) at 37 ${ }^{\circ} \mathrm{C}$ and their masses recorded daily for two weeks. 


\section{RESULTS}

\section{Synthesis}

$\alpha$-TCP was prepared via the solid state reaction between calcium carbonate and dibasic calcium phosphate dehydrate. Analysis of the resulting solid with FTIR and XRD confirmed that the correct polymorph was formed during the solid state reaction. The FTIR spectrum the $\mathrm{KBr}$ disc

of $\alpha$-TCP (Figure $1 \mathrm{~A}$ ) recorded in transmission mode showed a broad band at ca. $1055-954 \mathrm{~cm}^{-1}$ that is associated with symmetric P-O stretching and triply degenerate anti-symmetric P-O stretching; the broad band at 551-613 $\mathrm{cm}^{-1}$ is associated with triply degenerate anti-symmetric P$\mathrm{O}$ bending, and the shoulder at $471 \mathrm{~cm}^{-1}$ and the clearly discernable band at $430 \mathrm{~cm}^{-1}$ is associated with symmetric P-O stretching that are all characteristic of $\alpha$-TCP. ${ }^{34}$ Furthermore, the FTIR spectrum of pure $\alpha$-TCP (Figure $1 \mathrm{~B}$ ) recorded in ATR mode revealed clearly discernable peaks at 1077, 1085, 1027, 1012 and $998 \mathrm{~cm}^{-1}$ corresponding to the triply degenerate antisymmetric P-O stretching, and 976, 964 and $954 \mathrm{~cm}^{-1}$ corresponding to the symmetric P-O stretching, that are all characteristic of $\alpha$-TCP. ${ }^{34-36}$ The XRD spectrum of $\alpha$-TCP (Figure 1 C) revealed clear peaks at $2 \Theta=12.101,14.026,15.169,17.094,22.138,22.675,22.890,24.105$, 29.665, 3.0346, 30.709, 31.260, 32.089, 32.208, 34.209, 34.466, 36.434, 37.784, 38.94, 39.91 that are characteristic of $\alpha$-TCP. ${ }^{34,37}$

\section{Powder preparation}

Prior to inclusion in the cement formulations, the $\alpha$-TCP was ground first with a mortar and pestle and subsequently with a Mixer Mill MM 300 in a ball bearing grinding chamber. The resulting finely ground powder (Figure 2 and S1) was composed of irregularly shaped particles 
with a lognormal distribution (R-squared of 62.6\%). After conversion to a non-logarithmic scale, the 95\% confidence interval of mean particle surface area ranged from 100 to $428 \mu^{2}$ (Figure S2). While the particle sizes and shapes were irregular, the particle diameters were 10 to $20.7 \mu \mathrm{m}$ at the $95 \%$ confidence interval if the particles were assumed to be spherical.

\section{Characteristics of the CPCs}

Cement formulations were mixed, and all mechanical properties reported were recorded 24 hours after first mixing the formulations. Our control formulation (1) prepared from $\alpha$-TCP and hydroxyapatite suspended in disodium phosphate solution had a compressive modulus of ca. 100 MPa, a compressive strength of ca. $12 \mathrm{MPa}$ and a modulus of resilience of ca. $4000 \mathrm{~J} / \mathrm{m}^{3}$ (Table 1, Figure 3 and S3). Replacement of the disodium phosphate solution with bioactive PPP (formulation 2) resulted in a formulation that did not set within 24 hours and was therefore not investigated further. Interestingly, the addition of disodium phosphate (4 wt \%) to the bioactive PPP (i.e., formulation 3) promoted setting of the $\alpha$-TCP, resulting in a cement with a compressive modulus and compressive strength of ca. $55 \mathrm{MPa}$ and $3 \mathrm{MPa}$ respectively, and a modulus of resilience of ca. $40 \mathrm{~J} / \mathrm{m}^{3}$. Further reduction of the PPP volume within cement formulation 4 produced a cement with a compressive modulus of ca. $440 \mathrm{MPa}$, a compressive strength of ca. $22 \mathrm{MPa}$ and a modulus of resilience of ca. $5400 \mathrm{~J} / \mathrm{m}^{3}$. We found that the addition of PGA sutures to $\alpha$-TCP and hydroxyapatite suspended in disodium phosphate solution (i.e., formulation 5) yielded composites with diminished compressive modulus and strength (ca. 50 MPa and 4 MPa respectively) and modulus of resilience (of ca. $510 \mathrm{~J} / \mathrm{m}^{3}$ ), relative to the analogous formulation (1) without the sutures. Formulation 6, incorporating equal quantities of disodium phosphate, CMC and gelatin, a small amount of PPP and Monofyl ${ }^{\circledR}$ sutures resulted in 
composites with a compressive modulus and strength of ca. $54 \mathrm{MPa}$ and 5 MPa respectively, and a modulus of resilience of ca. $40 \mathrm{~J} / \mathrm{m}^{3}$. Formulation 7 , incorporating more gelatin to formulation 6 (at the expense of the disodium phosphate), resulted in composites with a compressive modulus and strength of ca. $82 \mathrm{MPa}$ and $4 \mathrm{MPa}$ respectively, and a modulus of resilience of ca. $250 \mathrm{~J} / \mathrm{m}^{3}$. Formulation 8, based on formulation 4 with the addition of $0.8 \mathrm{wt} \%$ Monofyl ${ }^{\circledR}$ sutures, resulted in composites with a compressive modulus and strength of ca. $98 \mathrm{MPa}$ and 8 MPa respectively, and a modulus of resilience of ca. $1130 \mathrm{~J} / \mathrm{m}^{3}$. The addition of a greater quantity of sutures (1.5 wt \%, i.e., formulation 9) moderately decreased the compressive modulus and strength to ca. $87 \mathrm{MPa}$ and $7 \mathrm{MPa}$ respectively, however the modulus of resilience increased to ca. $2130 \mathrm{~J} / \mathrm{m}^{3}$, although this was not a statistically significant improvement. Finally, formulation 10 (formulation 8 with extra disodium phosphate at the expense of PPP) had further improved mechanical properties, with a compressive modulus and strength of ca. 265 MPa and 21 MPa respectively, similar to formulation 4.

CPCs are promising replacements for PMMA-based cements. We studied the mass change of a selection of the samples incubated in PBS at $37^{\circ} \mathrm{C}$ over the period of two weeks for three of the compositions studied: formulation 1 without sutures, formulation 5 with PGA sutures and formulation 8 with Monofyl ${ }^{\circledR}$ sutures, chosen toconfirm their stability with respect to mass loss for more than one week (Figure S4) after which the inflammatory response phase is complete and renewal and remodeling begins. ${ }^{38}$ Formulation 1 , without sutures was observed to swell and increase in mass moderately (ca. 1 to $2 \%$ ) over the first few days before gradually decreasing in mass to ca. $98 \%$ of their initial mass after one week and plateauing at ca. $97 \%$ of their initial mass after two weeks. Formulation 5 including PGA sutures was found to degrade more quickly, to ca. $94 \%$ of their initial mass after 1 week, and to ca. $93 \%$ of their initial mass after 2 weeks. 
By contrast, formulation 8 including Monofyl ${ }^{\circledR}$ sutures, CMC and a small amount of PPP, were found to be more stable to mass loss and remained swollen by ca. $2 \%$ after 2 weeks. While we expect that the composites would behave differently in the biological milieu in vivo in which there are a variety of other factors at play, this gives some indication that the cement formulations incorporating Monofyl ${ }^{\circledR}$ sutures were stable for a clinically relevant time scale (days-weeks).

\section{DISCUSSION}

We sought to develop CPC-based bone cements for the healing of bone defects with regenerative biomaterials. The composite materials incorporated $\alpha$-TCP and hydroxyapatite with combinations of biopolymer-based thickeners, a blood plasma wetting agent, and biodegradable polymer-based sutures. Calcium phosphates are major components of bones and teeth, typically in the form of hydroxyapatite, which represents $2 \mathrm{wt} \%$ of the calcium phosphate content of the composites described here. Hydroxyapatite is however not self-setting, consequently the majority of the solids in these composites was self-setting $\alpha$-TCP (98 wt \% of the calcium phosphate content of the composites described here) which is a biocompatible calcium phosphate that hydrolyses to form calcium-deficient hydroxyapatite. ${ }^{34}$

The $\alpha$-TCP used herein was ground to a size that yielded reproducible mechanical properties. ${ }^{18,19}$ Bone cement formulations require liquid-based wetting agents to suspend the calcium phosphates within. Blood plasma, such as platelet poor plasma (PPP) is a source of growth factors known to promote the formation of new bone matrix ${ }^{39}, 40$ and was one of the components incorporated in some of the wetting agent formulations investigated. Aqueous solutions of disodium phosphate (4 wt \%) have been shown to promote setting of $\alpha-\mathrm{TCP}^{41}$ and was used in 
the majority of the wetting agent formulations. Various combinations of biopolymers including CMC and gelatin were used to viscosify the suspensions ${ }^{42}$ and potentially promote cell adhesion. ${ }^{43}$ Furthermore, we sought to counteract the tendency of calcium phosphate cements tend to fail by brittle fracture and crack propagation ${ }^{23,26}$ through reinforcement with biodegradable fibers, ${ }^{23,26,44-51}$ using either Monofyl ${ }^{\circledR}$ or PGA sutures. While in the short term the 4-0 sutures were intended to reinforce the composites, their long term degradation in vivo has the potential to leave channels of ca. $150 \mu \mathrm{m}$ within the cement matrix that would be suitable for the infiltration of osteoclasts which may promote remodeling of the CPC, possibly facilitating vascularization. ${ }^{16,52-54}$ Since the mechanical strain and accordingly turnover rate of low load bearing bone tissue such as sinuses is low, and apatitic cements resorb slowly, we expect bone ingrowth to exceed the degradation of our formulations. ${ }^{28,55}$ While coordinating CPC degradation rates with the rate of bone ingrowth is important, it would also be necessary to assess the mechanical stability of CPC treated bone over longer time periods which is outside the scope of the present study.

For low load bearing applications such as sinus augmentation or filling extraction sites, we require CPC formulations with Young's moduli of ca. 0.05-1GPa. ${ }^{17}$ Consequently we assessed the compressive moduli and strengths of the CPC formulations via compressive extension tests (Table 1).

Our control CPC formulation (1) prepared from $\alpha$-TCP and hydroxyapatite suspended in disodium phosphate solution, was expected to be the least bioactive, and had a compressive modulus of ca. $100 \mathrm{MPa}$ and a compressive strength of ca. $11 \mathrm{MPa}$, which would be acceptable for low load bearing applications. ${ }^{17,18}$ Complete replacement of the disodium phosphate solution 
with bioactive PPP (formulation 2) yielded a formulation that did not set within 24 hours; however, the addition of disodium phosphate ( $4 \mathrm{wt} \%$ ) to the PPP (i.e., formulation 3) promoted setting of the $\alpha$-TCP, ${ }^{41}$ yielding a conceptually bioactive CPC with a compressive modulus and compressive strength of ca. $55 \mathrm{MPa}$ and $3 \mathrm{MPa}$ respectively, which may also be clinically relevant. Viscosification of the CPC formulations was achieved through the addition of CMC, and formulation 4, including disodium phosphate and PPP, yielded a bioactive CPC with a compressive modulus of ca. $440 \mathrm{MPa}$, a compressive strength of ca. $22 \mathrm{MPa}$ and a modulus of resilience of ca. $5400 \mathrm{~J} / \mathrm{m}^{3}$, the highest of all of the formulations reported herein. With a view to further enhance the long term potential bioactivity of the cement formulations we investigated the addition of biodegradable sutures. Inclusion of 4-0 biodegradable sutures in the formulations has the potential to reinforce the CPC composites for some time after their application at the site of the bone defect, and moreover, the potential to leave channels of ca. $150 \mu \mathrm{m}$ within the CPC matrix after their degradation. These channels, in vivo, would allow for the infiltration of osteoclasts and promote remodeling of the cement. ${ }^{16,52-54}$ We found that the addition of PGA sutures to $\alpha$-TCP and hydroxyapatite suspended in disodium phosphate solution (i.e., formulation 5) yielded CPC composites with diminished compressive modulus and strength (ca. 50 MPa and $4 \mathrm{MPa}$ respectively) relative to the analogous formulation (1) without the sutures. We postulate this observation to be a result of the interference of the L-lysine and/or the monolaurin coating on the PGA sutures with the CPC setting process. Monofyl ${ }^{\circledR}$ sutures represent an attractive alternative to PGA sutures because they are uncoated and the composites are stable with respect to mass loss for more than one week (Figure S4) after which the inflammatory response phase is complete and renewal and remodeling begins, ${ }^{58}$ consequently, we utilized these in the rest of the CPC formulations. 
Bones are rich in cell-adhesive collagens, and the inclusion of gelatin (partially hydrolyzed collagen) to the formulations was intended to render them simultaneously viscous and more cell adhesive. ${ }^{27,59,60}$ Formulation 6, incorporating equal quantities of disodium phosphate, CMC and gelatin, a small amount of PPP and Monofyl ${ }^{\circledR}$ sutures yielded CPC composites with a compressive modulus and strength of ca. $54 \mathrm{MPa}$ and $5 \mathrm{MPa}$ respectively. Formulation 7, incorporating more gelatin to formulation 6 (at the expense of the disodium phosphate), yielded CPC composites with a compressive modulus and strength of ca. $82 \mathrm{MPa}$ and $4 \mathrm{MPa}$, respectively. Formulation 8, based on formulation 4 with the addition of 0.8 wt \% Monofyl ${ }^{\circledR}$ sutures, yielded CPC composites with a compressive modulus and strength of ca. $98 \mathrm{MPa}$ and 8 MPa respectively, and a modulus of resilience of ca. $1130 \mathrm{~J} / \mathrm{m}^{3}$, which was markedly lower than formulation 4 without the sutures. The addition of a greater quantity of sutures (1.5 wt \%), yielding formulation 9, moderately decreased the compressive modulus and strength to ca. 87 MPa and 7 MPa respectively, the modulus of resilience was observed to increase to ca. 2130 $\mathrm{J} / \mathrm{m}^{3}$, although this was not a statistically significant improvement. Finally, formulation 10 (formulation 8 with extra disodium phosphate at the expense of PPP) had further improved mechanical properties, with a compressive modulus and strength of ca. $265 \mathrm{MPa}$ and $21 \mathrm{MPa}$ respectively, and a modulus of resilience of ca. $1420 \mathrm{~J} / \mathrm{m}^{3}$, similar to formulation 4 .

Considering the mechanical properties for all cements in Table 1, we find formulations 1, 3, 4, 5, 6, 7, 8, 9 and 10 to be suitable for low load bearing applications, of which formulations 4 and 10 have significantly improved mechanical properties as well as regenerative potential. We observed rheological interactions that prevented CPC setting when using high volumes of PPP wetting agent, and we suggest therefore that further characterization of blood and CPC 
interactions are necessary, yet we overcame this limitation using a 4\% disodium phosphate solution, CMC, and lower volumes of PPP.

\section{CONCLUSIONS}

Bone cements enhanced by regenerative strategies are promising biomaterials for the healing of bone defects. The preparation of injectable CPC-based composites incorporating $\alpha$-TCP, hydroxyapatite, biopolymer-thickened wetting agents, and optionally, biodegradable polymerbased sutures yields biodegradable bone-like composites, of which, formulations 1, 3, 4, 5, 6, 7, 8, 9 and 10 had compressive moduli suitable for low load bearing applications. ${ }^{18}$ While we did not observe a higher modulus of resilience by suture reinforcement in this study, we hypothesize the surface modifications of suture inclusions may be able to increase interfacial strength with the CPC composite, as would inclusion of longer sections of sutures. This increased strength may facilitate a higher modulus of resilience in the composite cement formulation and facilitate the application of such composites in medium and high load bearing applocations. The CPC-based bone cements with regenerative potential reported herein have potential as replacements for nonresorbable cements such as those based on PMMA and conventional CPC formulations without the potential for macropore formation, ${ }^{19}$ with advantages including the potential for coadministration of cells, drugs and proteins without thermal damage. ${ }^{61-64}$ Furthermore, simple alterations to the CPC compositions of the cement formulations will facilitate further modulation of their osteoconductive and surgical handling properties. Future studies will focus on optimization of CPC formulations for injection and characterizing the dynamic nature of CPC mechanical properties in vitro. Moreover, we will optimize suture lengths/loadings and characterize the long term degradation of the resulting scaffolds. 


\section{ACKNOWLEDGMENTS}

At the Department of Chemistry at the University of Texas at Austin we thank the teaching labs

for access to an IR spectrometer and Dr. Vincent M. Lynch for assistance with X-ray diffraction data collection. We thank the National Science Foundation for Grant No. 0741973 that was used

to purchase the Rigaku R-Axis Spider diffractometer. At the Department of Mechanical

Engineering at the University of Texas at Austin we thank Professor David L. Bourell for access

to a furnace and Abhimanyu Bhat for assistance with its use.

\section{REFERENCES}

[1] Kretlow JD, Klouda L, Mikos AG, Injectable matrices and scaffolds for drug delivery in tissue engineering. Adv. Drug. Deliver. Rev. 2007; 59: 263-273.

[2] Kretlow JD, Young S, Klouda L, Wong M, Mikos AG, Injectable Biomaterials for Regenerating Complex Craniofacial Tissues. Adv. Mater. 2009; 21: 3368-3393.

[3] Temenoff JS, Mikos AG, Injectable biodegradable materials for orthopedic tissue engineering. Biomaterials 2000; 21: 2405-2412.

[4] Rahman CV, Saeed A, White LJ, Gould TWA, Kirby GTS, Sawkins MJ, Alexander C, Rose FRAJ, Shakesheff KM, Chemistry of Polymer and Ceramic-Based Injectable Scaffolds and Their Applications in Regenerative Medicine. Chem. Mater. 2012; 24: 781-795.

[5] Rho JY, Kuhn-Spearing L, Zioupos P, Mechanical properties and the hierarchical structure of bone. Med. Eng. Phys. 1998; 20: 92-102.

[6] Amini AR, Laurencin CT, Nukavarapu SP, Bone tissue engineering: recent advances and challenges. Crit. Rev. Biomed. Eng. 2012; 40: 363-408.

[7] Khan Y, Yaszemski MJ, Mikos AG, Laurencin CT, Tissue Engineering of Bone: Material and Matrix Considerations. J. Bone Joint Surg. Am. 2008; 90A: 36-42.

[8] Stevens MM, Biomaterials for bone tissue engineering. Mater. Today 2008; 11: 18-25.

[9] Porter JR, Ruckh TT, Popat KC, Bone tissue engineering: a review in bone biomimetics and drug delivery strategies. Biotechnol. Progr. 2009, 25, 1539-1560.

[10] Lewis G, Viscoelastic properties of injectable bone cements for orthopaedic applications: state-of-the-art review. J. Biomed. Mater. Res. B 2011; 98B: 171-191.

[11] Hutmacher DW, Scaffolds in tissue engineering bone and cartilage. Biomaterials 2000; 21: 2529-2543.

[12] Mano JF, Sousa RA, Boesel LF, Neves NM, Reis RL, Bioinert, biodegradable and injectable polymeric matrix composites for hard tissue replacement: state of the art and recent developments. Compos. Sci. Technol. 2004, 64, 789-817.

[13] Salgado AJ, Coutinho OP, Reis RL, Bone tissue engineering: state of the art and future trends. Macromol. Biosci. 2004; 4: 743-765.

[14] Bohner M, Galea L, Doebelin N, Calcium phosphate bone graft substitutes: Failures and hopes. J. Eur. Ceram. Soc. 2012; 32: 2663-2671. 
[15] Barralet JE, Grover L, Gaunt T, Wright AJ, Gibson IR, Preparation of macroporous calcium phosphate cement tissue engineering scaffold. Biomaterials 2002; 23: 3063-3072.

[16] Hertz A, Bruce IJ, Inorganic materials for bone repair or replacement applications. Nanomedicine 2007; 2: 899-918.

[17] Saiz E, Zimmermann EA, Lee JS, Wegst UGK, Tomsia AP, Perspectives on the role of nanotechnology in bone tissue engineering. Dental Mater. 2013; 29: 103-115.

[18] Zhang J, Liu W, Schnitzler V, Tancret F, Bouler JM, Calcium phosphate cements for bone substitution: Chemistry, handling and mechanical properties. Acta Biomaterialia 2014; 10: 10351049.[19] Wagoner Johnson AJ, Herschler BA, A review of the mechanical behavior of CaP and $\mathrm{CaP} /$ polymer composites for applications in bone replacement and repair. Acta Biomaterialia 2011;7:16-30.

[20] Arora M, Chan EK, Gupta S, Diwan AD, Polymethylmethacrylate bone cements and additives: A review of the literature. World J. Orthoped. 2013; 4: 67-74.

[21] Benyamin R, Vallejo R, Vertebroplasty. Techniques in Regional Anesthesia \& Pain Management 2005; 9: 62-67.

[22] Ginebra MP, Canal C, Espanol M, Pastorino D, Montufar EB, Calcium phosphate cements as drug delivery materials. Adv. Drug Deliver. Rev. 2012; 64: 1090-1110.

[23] Kruger R, Groll J, Fiber reinforced calcium phosphate cements - on the way to degradable load bearing bone substitutes? Biomaterials 2012; 33: 5887-5900.

[24] Larsson S, Bauer TW, Use of injectable calcium phosphate cement for fracture fixation: a review. Clin. Orthop. Relat. R. 2002; 395: 23-32.

[25] Ginebra MP, Traykova T, Planell JA, Calcium phosphate cements as bone drug delivery systems: a review. J. Control. Release 2006; 113: 102-110.

[26] Canal C, Ginebra MP, Fibre-reinforced calcium phosphate cements: a review. J. Mech. Behav. Biomed. 2011; 4: 1658-1671.

[27] O'Hara RM, Orr JF, Buchanan FJ, Wilcox RK, Barton DC, Dunne NJ, Development of a bovine collagen-apatitic calcium phosphate cement for potential fracture treatment through vertebroplasty. Acta Biomater. 2012; 8: 4043-4052.

[28] Schlegel KA, Rupprecht S, Petrovic RS, Honert C, Srour S, von Willmowsky C, Felszegy E, Nkenke E, Lutz R, Preclinical animal model for de novo bone formation in human maxillary sinus. Oral Surg. Oral Med. Oral Pathol. Oral Radiol. Endod. 2009; 108(3):e37-44.

[29] Tarsuslugil SM, O'Hara RM, Dunne NJ, Buchanan FJ, Orr JF, Barton DC, Wilcox RK, Development of calcium phosphate cement for the augmentation of traumatically fractured porcine specimens using vertebroplasty. J. Biomech. 2013; 46: 711-715.

[30] Cicek G, Aksoy EA, Durucan C, Hasirci N, Alpha-tricalcium phosphate ( $\alpha$-TCP): solid state synthesis from different calcium precursors and the hydraulic reactivity. J. Mater. Sci. Mater. Med.

2011; 22: 809-817.

[31] Bigi A, Bracci B, Panzavolta S, Effect of added gelatin on the properties of calcium phosphate cement. Biomaterials, 2004; 25, 2893-2899.

[32] Kim SY., Jeon SH, Setting properties, mechanical strength and in vivo evaluation of calcium phosphate-based bone cements. J. Ind. Eng. Chem. 2012; 18: 128-136.

[33] Gu T, Shi H, Ye J, Reinforcement of calcium phosphate cement by incorporating with highstrength $\beta$-tricalcium phosphate aggregates. J. Biomed. Mater. Res. B 2012; 100B: 350-359.

[34] Carrodeguas RG, De Aza S, $\alpha$-Tricalcium phosphate: synthesis, properties and biomedical applications. Acta Biomater. 2011; 7: 3536-3546. 
[35] Jillavenkatesa A, Condrate RA, The Infrared and Raman Spectra of $\beta$-and $\alpha$-Tricalcium Phosphate $\left(\mathrm{Ca}_{3}\left(\mathrm{PO}_{4}\right)_{2}\right)$ Spectrosc. Lett. 1998, 31, 1619-1634.

[36] Bhatnaga VM, Infrared spectrum of strontium hydroxyapatite. Experientia 1967; 23: 697699.

[37] Mathew M, Schroeder LW, Dickens B, Brown WE, The crystal structure of $\alpha-\mathrm{Ca}_{3}\left(\mathrm{PO}_{4}\right)_{2}$. Acta Crystall. B 1977, 33, 1325-1333.

[38] Mountziaris PM, Mikos AG, Modulation of the inflammatory response for enhanced bone tissue regeneration. Tissue Eng. Part B 2008; 14: 179-186.

[39] Arpornmaeklong P, Kochel M, Depprich R, Kubler NR, Wurzler KK, Influence of plateletrich plasma (PRP) on osteogenic differentiation of rat bone marrow stromal cells. An in vitro study. Int. J. Oral Max. Surg. 2004; 33: 60-70.

[40] Sebben AD, Hoff G, Klein CP, de Freitas TA, Assad C, dos Santos LA, Silva JB, Comparative study on use of platelet-rich plasma alone and in combination with alpha-tricalcium phosphate cement for bone repair in rats. Rev. Brasil. Ortop. 2012; 47: 505-512.

[41] Ginebra MP, Fernandez E, Boltong MG, Bermudez O, Planell JA, Driessens FC, Compliance of an apatitic calcium phosphate cement with the short-term clinical requirements in bone surgery, orthopaedics and dentistry. Clin. Mater. 1994; 17: 99-104.

[42] Cherng A, Takagi S, Chow LC, Effects of hydroxypropyl methylcellulose and other gelling agents on the handling properties of calcium phosphate cement. J. Biomed. Mater. Res. 1997; 35: 273-277.

[43] Perez RA, Ginebra MP, Injectable collagen/ $\alpha$-tricalcium phosphate cement: collagen-mineral phase interactions and cell response. J. Mater. Sci. Mater. Med. 2013; 24: 381-393.

[45] Mohanty AK, Misra M, Hinrichsen G, Biofibres, biodegradable polymers and biocomposites: An overview. Macromol. Mater. Eng. 2000; 276: 1-24.

[46] Faruk O, Bledzki AK, Fink HP, Sain M, Progress Report on Natural Fiber Reinforced Composites. Macromol. Mater. Eng. 2014; 299: 9-14.

[47] Pandey JK, Ahn SH, Lee CS, Mohanty AK, Misra M, Recent Advances in the Application of Natural Fiber Based Composites. Macromol. Mater. Eng. 2010; 295: 975-989.

[48] dos Santos LA, Carrodeguas RG, Boschi AO, de Arruda ACF, Fiber-enriched double-setting calcium phosphate bone cement. J. Biomed. Mater. Res. A 2003; 65A: 244-250.

[49] Burguera EF, Xu HHK, Takagi S, Chow LC, High early-strength calcium phosphate bone cement: Effects of dicalcium phosphate dehydrate and absorbable fibers. J. Biomed. Mater. Res. A 2005; 75A: 966-975.

[50] Fakirov S, Nano-/microfibrillar polymer-polymer and single polymer composites: The converting instead of adding concept. Compos. Sci. Technol. 2013; 89: 211-225.

[51] Zhang Y, Xu HHK, Effects of synergistic reinforcement and absorbable fiber strength on hydroxyapatite bone cement. J. Biomed. Mater. Res. A 2005; 75A: 832-840.

Buchanan F, Gallagher L, Jack V, Dunne N, Short-fibre reinforcement of calcium phosphate bone cement, Proc. Inst. Mech. Eng. H. 2007; 221: 203-211.

[52] Costa PF, Vaquette C, Zhang QY, Reis RL, Ivanovski S, Hutmacher DW, Advanced tissue engineering scaffold design for regeneration of the complex hierarchical periodontal structure. $J$. Clin. Periodontol. 2014; 41: 283-294.

[53] Hofmann S, Hilbe M, Fajardo RJ, Hagenmuller H, Nuss K, Arras M, Muller R, von Rechenberg B, Kaplan DL, Merkle HP, Meinel L, Remodeling of tissue-engineered bone structures in vivo. Eur. J. Pharm. Biopharm. 2013; 85: 119-129. 
[54] Gerhardt LC, Widdows KL, Erol MM, Nandakumar A, Roqan IS, Ansari T, Boccaccini AR, Neocellularization and neovascularization of nanosized bioactive glass-coated decellularized trabecular bone scaffolds. J. Biomed. Mater. Res. A 2013; 101A: 827-841.

[55] Clarke B, Normal bone anatomy and physiology. Clin. J. Am. Soc. Nephrol. 2008, 3, S131S139.

[56] Mosekilde L, Mosekilde L, Normal vertebral body siz and compressive strength: relations to age and to vertebral and iliac trabecular bone compressive strength. Bone 1986; 7: 207-212.

[57] Blattert TR, Jestaedt L, Weckbach A, Suitability of a calcium phosphate cement in osteoporotic vertebral body fracture augmentation. Spine, 2009, 34, 108-114.

[58] Sugawara A, Asaoka K, Ding SJ, Calcium phosphate-based cements: clinical needs and recent progress. J. Mater. Chem. B 2013; 1: 1081.

[59] Reinstorf A, Ruhnow M, Gelinsky M, Pompe W, Hempel U, Wenzel KW, Simon P, Phosphoserine - a convenient compound for modification of calcium phosphate bone cement collagen composites. J. Mater. Sci. Mater. Med. 2004; 15: 451-455.

[60] Sagar N, Soni VP, Bellare JR, Influence of carboxymethyl chitin on stability and biocompatibility of 3D nanohydroxyapatite/gelatin/carboxymethyl chitin composite for bone tissue engineering. J. Biomed. Mater. Res. B 2012; 100B: 624-636.

[61] Murphy MB, Moncivais K, Caplan AI, Mesenchymal stem cells: environmentally responsive therapeutics for regenerative medicine. Exp. Mol. Med. 2013; 45: e54.

[62] Murphy MB, Blashki D, Buchanan RM, Tasciotti E, Engineering a Better Way to Heal Broken Bones. Chem. Eng. Prog. 2010; 106: 37-43.

[63] Young S, Patel ZS, Kretlow JD, Murphy MB, Mountziaris PM, Baggett LS, Ueda H, Tabata Y, Jansen JA, Wong M, Mikos AG, Dose effect of dual delivery of vascular endothelial growth factor and bone morphogenetic protein-2 on bone regeneration in a rat critical-size defect model. Tissue Eng. Part A 2009; 15: 2347-2362.

[64] Rodriguez I, Saxena G, Sell S, Bowlin G, Mineralization and characterization of composite lyophilized gelatin sponges intended for early bone regeneration. Bioengineering 2014; 1(1):6284. 


\section{FIGURES}

Figure 1. A) The FTIR spectrum the $\mathrm{KBr}$ disc of $\alpha$-TCP recorded in transmission mode. B) The FTIR spectrum of pure $\alpha$-TCP (Figure 1 B) recorded in ATR mode. C) XRD spectrum of $\alpha$-TCP.
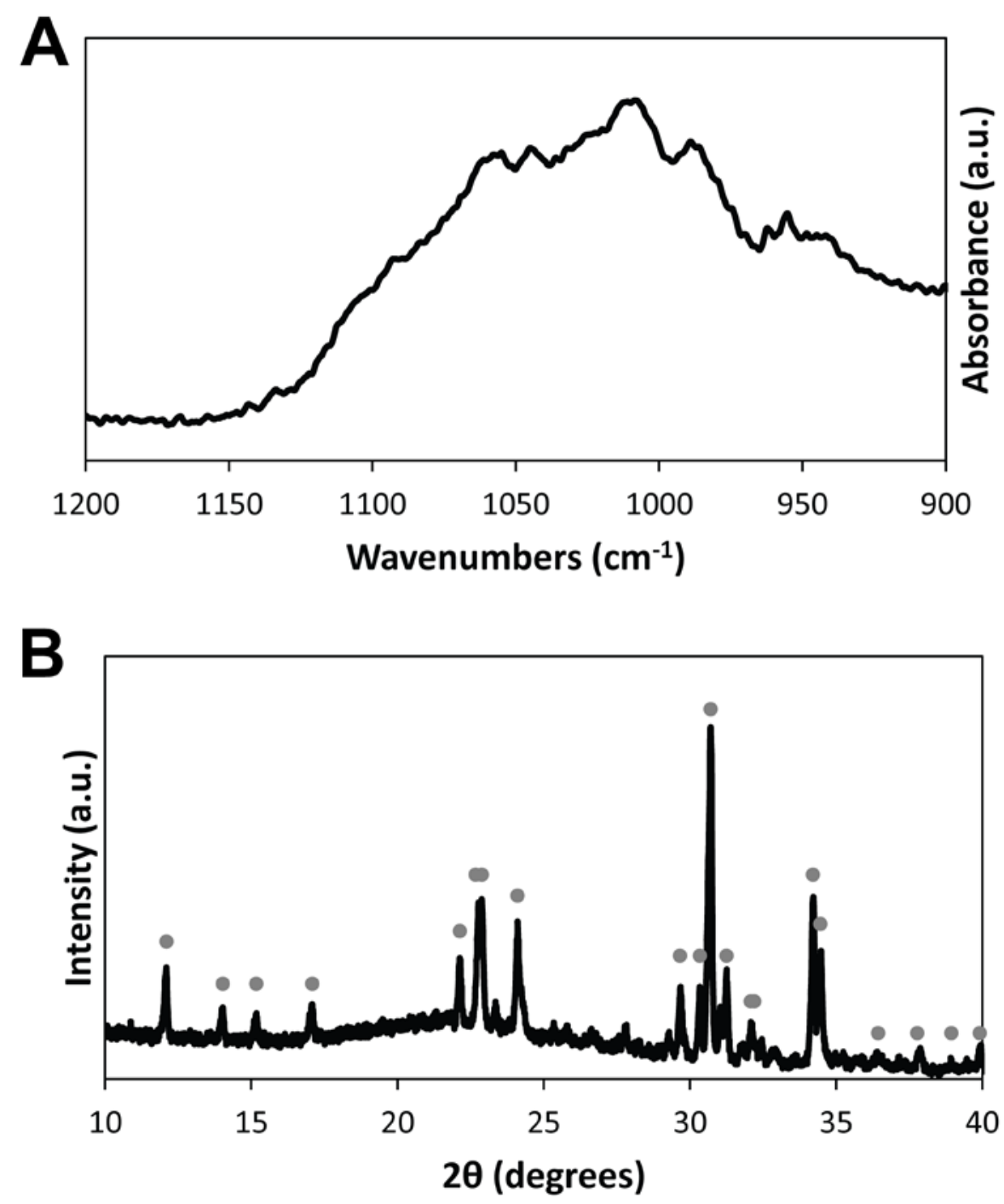
Figure 2. $\alpha$-TCP powder. A) Scanning Electron Microscope (SEM) image of the same powder obtained on a Zeiss Supra 40 VP SEM (scale bar represents $200 \mu \mathrm{m}$ ). B) ImageJ-derived contour maps of SEM images from which the particle size distribution of $\alpha$-TCP particles was determined.
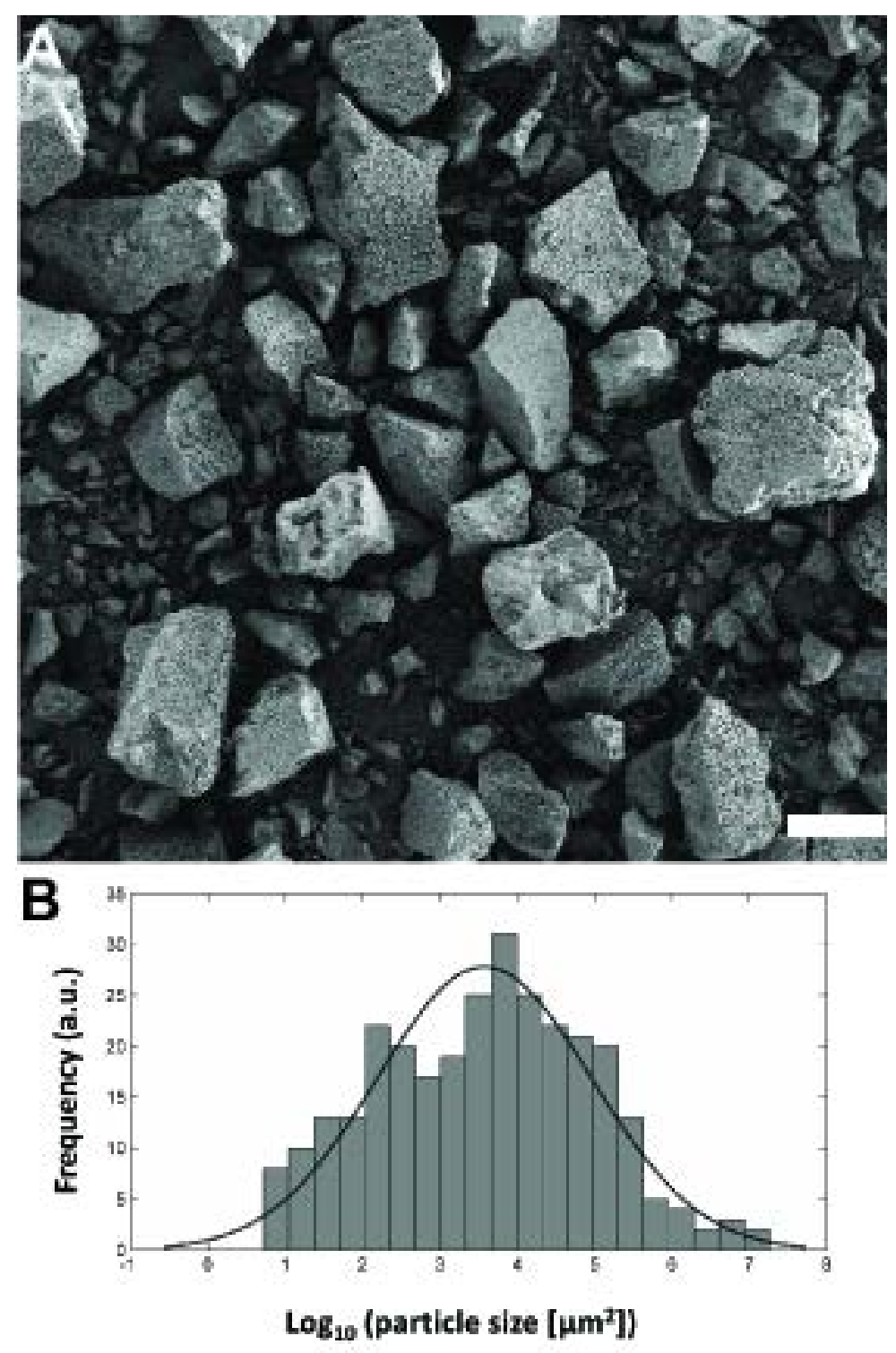
Figure 3. Mechanical properties of the CPC formulations described here. A) Box plot for compressive modulus data, * = significant from group 4; ** = significant from group 10. B) Box plot for ultimate strength data, * = significant from group $1 ; * *=$ significant from group 4 and 10. C) Box plot for modulus of resilience data, * = significant from group 1; ** = significant from group 4.
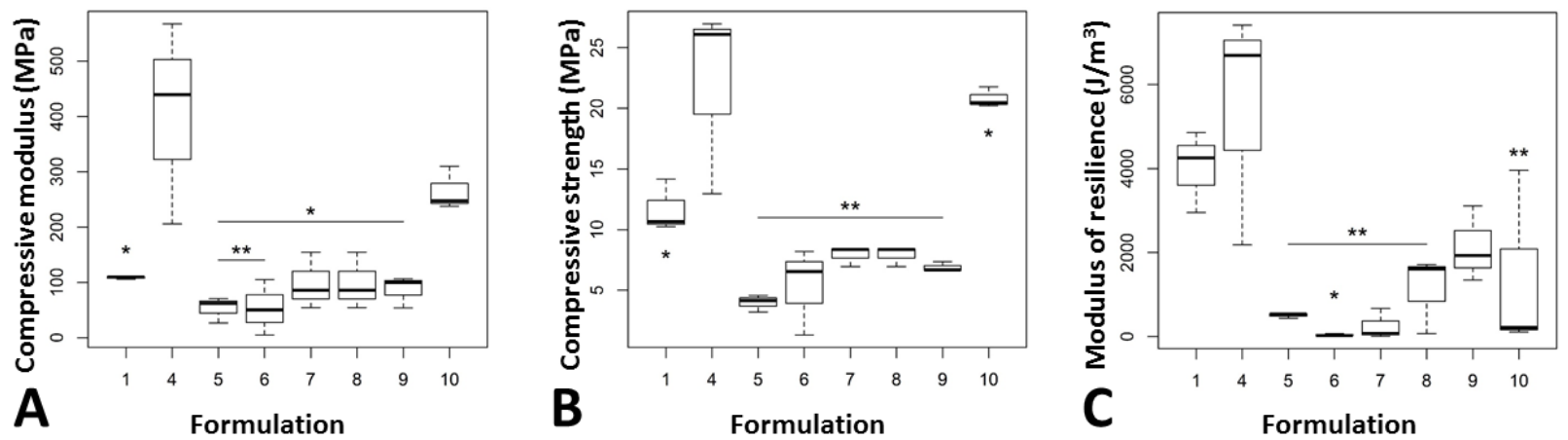
Table 1. Compositions and mechanical properties of injectable cement formulations.

\begin{tabular}{|c|c|c|c|c|c|c|c|c|c|c|}
\hline \multirow[t]{2}{*}{ Formulation } & \multicolumn{5}{|c|}{ Wetting agents [\%] } & \multicolumn{2}{|c|}{$\begin{array}{l}\text { Suture inclusion } \\
\text { [wt \%] }\end{array}$} & \multirow{2}{*}{$\begin{array}{l}\text { Compressive } \\
\text { Modulus, } \\
{[\mathrm{MPa}]}\end{array}$} & \multirow{2}{*}{$\begin{array}{l}\text { Compressive } \\
\text { Strength, } \\
\text { [MPa] }\end{array}$} & \multirow{2}{*}{$\begin{array}{l}\text { Modulus } \\
\text { of } \\
\text { Resilience, } \\
{\left[\frac{\mathrm{J}}{\mathrm{m}^{3}}\right]}\end{array}$} \\
\hline & $\mathrm{Na}_{2} \mathrm{HPO}_{4}{ }^{\mathrm{a}}$ & $\mathrm{CMC}^{\mathrm{b}}$ & Gelatin $^{\mathrm{c}}$ & PPP & $\mathrm{PPP} / \mathrm{Na}_{2} \mathrm{HPO}_{4}{ }^{\mathrm{d}}$ & Monofyl ${ }^{\circledR}$ & PGA & & & \\
\hline 1 & 100 & 0 & 0 & 0 & 0 & 0 & 0 & $108 \pm 2$ & $12 \pm 6$ & $4020 \pm 970$ \\
\hline 2 & 0 & 0 & 0 & 100 & 0 & 0 & 0 & N/A & N/A & N/A \\
\hline 3 & 0 & 0 & 0 & 0 & 100 & 0 & 0 & $55 \pm 2$ & $3 \pm 0.1$ & $40 \pm 4$ \\
\hline 4 & 60 & 30 & 0 & 10 & 0 & 0 & 0 & $404 \pm 40$ & $22 \pm 2$ & $\begin{array}{l}5430 \pm \\
2840\end{array}$ \\
\hline 5 & 100 & 0 & 0 & 0 & 0 & 0 & 0.8 & $53 \pm 23$ & $4 \pm 1$ & $510 \pm 60$ \\
\hline 6 & 30 & 30 & 30 & 10 & 0 & 0.8 & 0 & $54 \pm 5$ & $5 \pm 3$ & $40 \pm 30$ \\
\hline 7 & 0 & 30 & 60 & 10 & 0 & 0.8 & 0 & $82 \pm 8$ & $4 \pm 3$ & $250 \pm 360$ \\
\hline 8 & 60 & 30 & 0 & 10 & 0 & 0.8 & 0 & $98 \pm 10$ & $8 \pm 1$ & $1130 \pm 920$ \\
\hline 9 & 60 & 30 & 0 & 10 & 0 & 1.5 & 0 & $87 \pm 29$ & $7 \pm 2$ & $2130 \pm 900$ \\
\hline 10 & 70 & 30 & 0 & 0 & 0 & 0.8 & 0 & $265 \pm 39$ & $21 \pm 2$ & $\begin{array}{l}1420 \pm \\
2190\end{array}$ \\
\hline
\end{tabular}

Mechanical properties are reported \pm the standard deviations. Wetting agents comprised $34 \mathrm{wt} \%$ of the cement mass and calcium phosphates comprised $66 \mathrm{wt} \%$ (calcium phosphates were a mixture of $\alpha$-TCP (98 wt \%) and hydroxyapatite (2 wt \%)). a) Stock solution A: $\mathrm{Na}_{2} \mathrm{HPO}_{4} 4$ wt \% in DD $\mathrm{H}_{2} \mathrm{O}$; b) Stock solution B: CMC 1 wt \% in stock solution A; c) Stock solution C: Gelatin 5 wt \% in $\mathrm{DD}_{2} \mathrm{O}$; d) Stock solution D: PPP supplemented with 4 wt $\% \mathrm{Na}_{2} \mathrm{HPO}_{4}$. 


\section{Supplementary information}

Mechanical properties of $\alpha$-tricalcium phosphate-based bone cements incorporating regenerative biomaterials for filling bone defects exposed to low mechanical loads.

Authors: Reed Harrison, ${ }^{1}$ Zachary K. Criss, ${ }^{1 \dagger}$ Lacie Feller, ${ }^{1 \dagger}$ Shan P. Modi, ${ }^{1 \dagger}$ John G. Hardy, ${ }^{1,2 *}$ Christine E. Schmidt, ${ }^{1,2 *}$ Laura J. Suggs ${ }^{1 *}$ and Matthew B. Murphy ${ }^{1 *}$

Affiliations: 1) Department of Biomedical Engineering, The University of Texas at Austin, Austin, TX 78712. 2) J. Crayton Pruitt Family Department of Biomedical Engineering, University of Florida, Biomedical Sciences Building JG-53, P.O. Box 116131, Gainesville, FL 32611-6131.

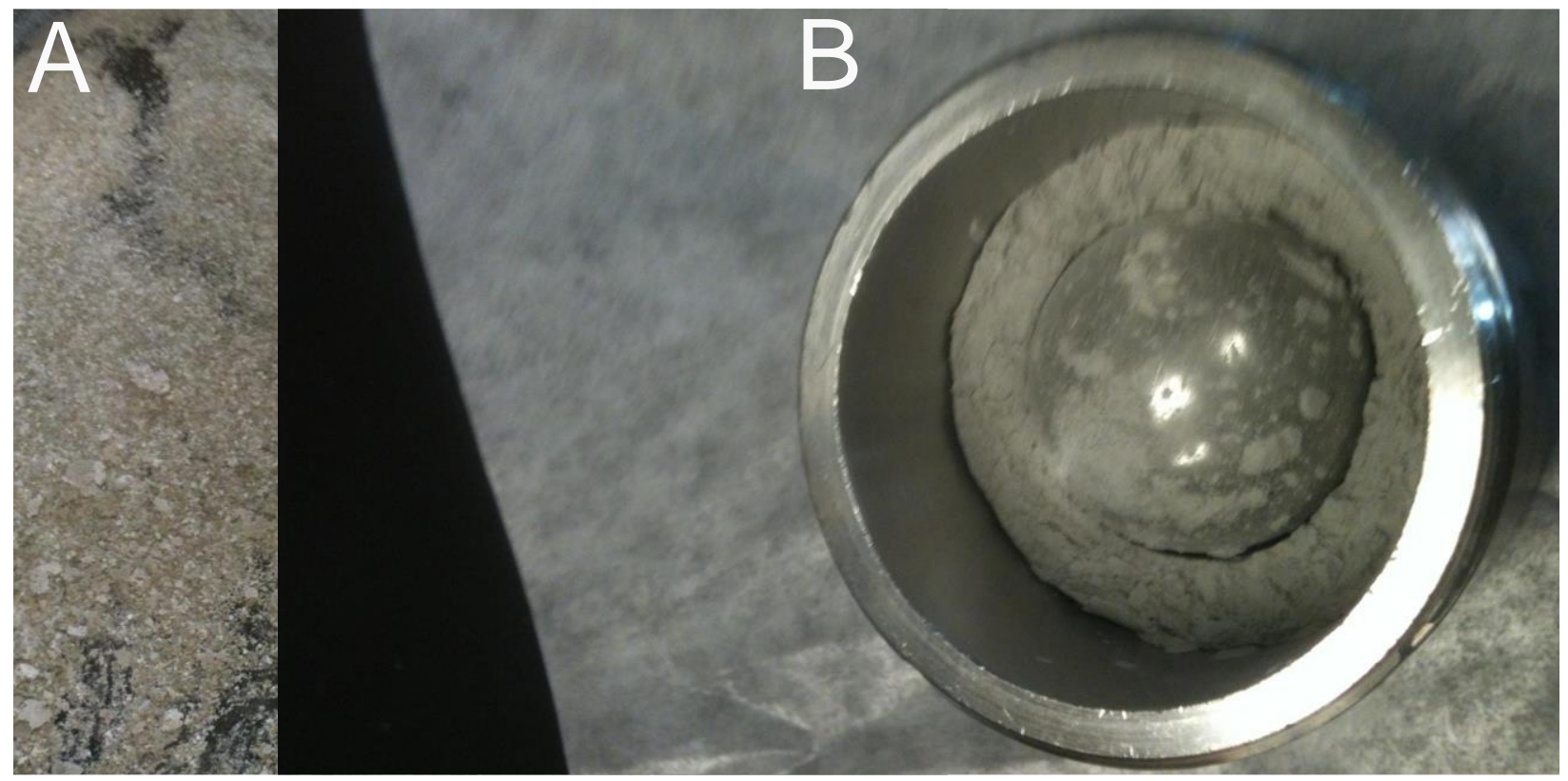

Figure S1. $\alpha$-TCP powder. A) Photograph of the solid isolated from the furnace. Image width $=5$ cm. B) Photograph of the powder obtained after using the Mixer Mill MM 300 for 30 minutes. Image width $=5 \mathrm{~cm}$. 
Fitted Distribution of Particle Size

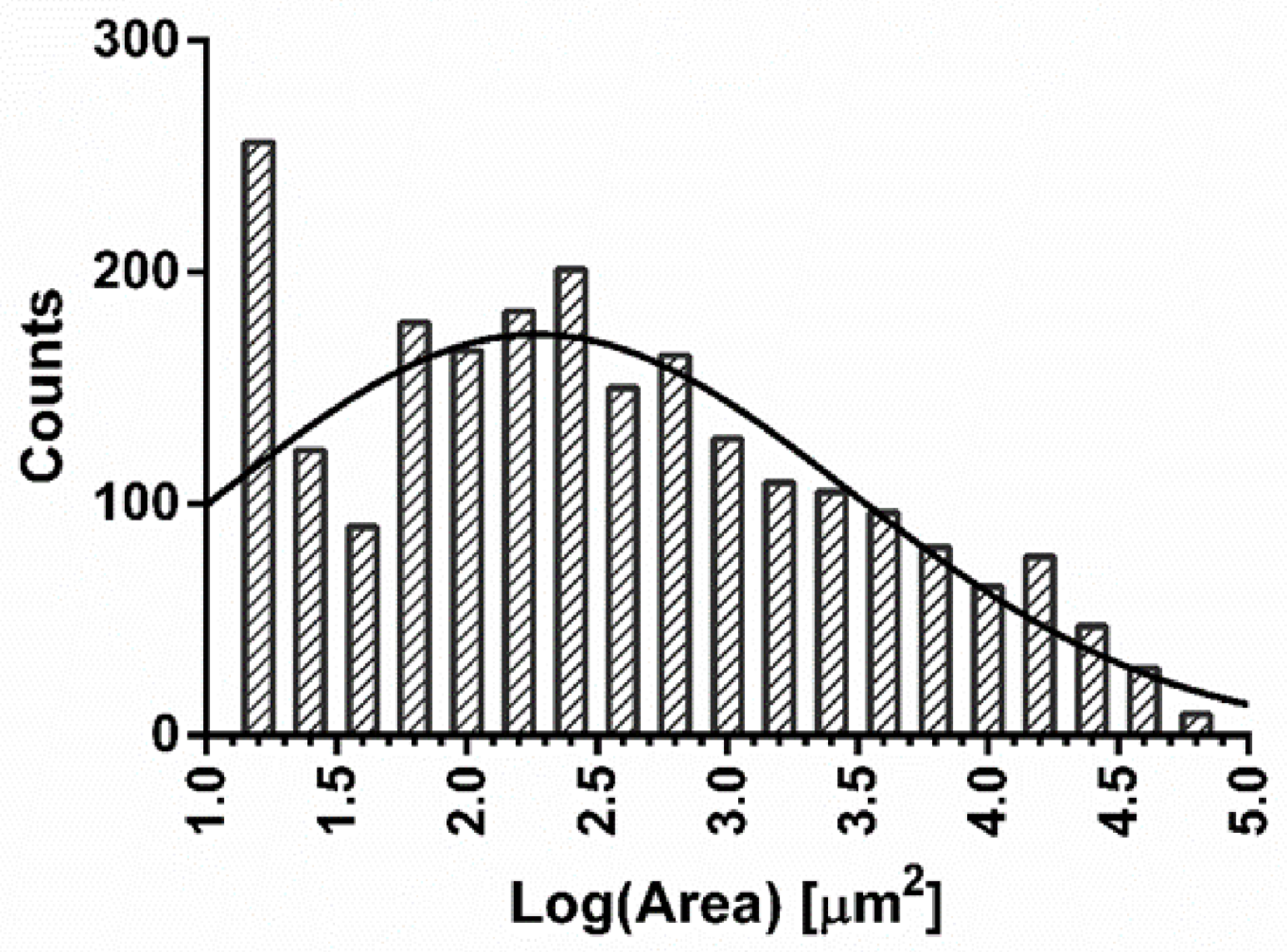

Figure S2. $\alpha$-TCP powder particle surface area distribution. 

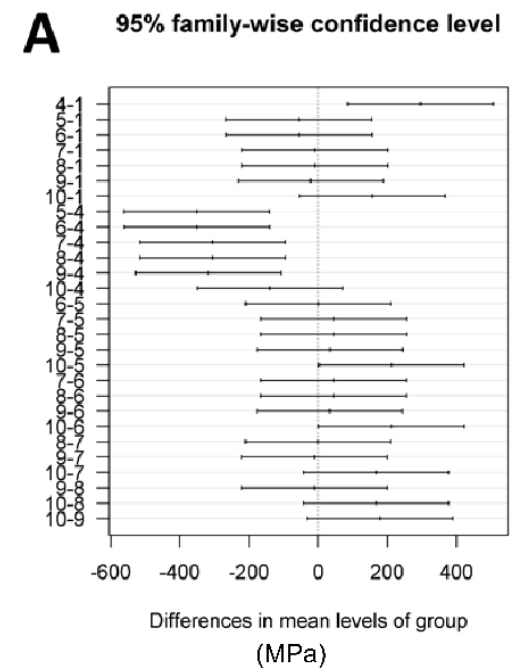
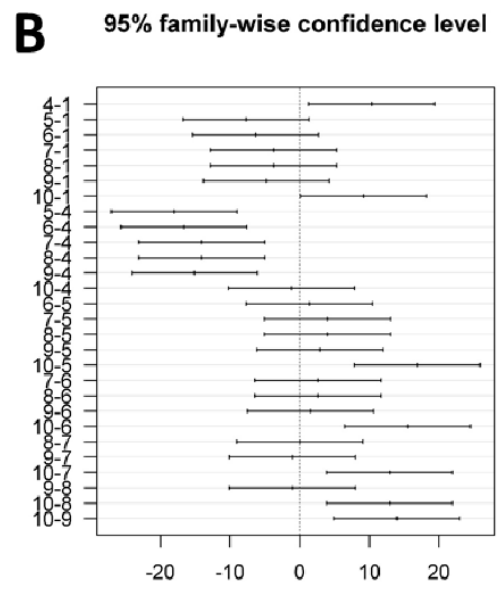

Differences in mean levels of group (MPa)
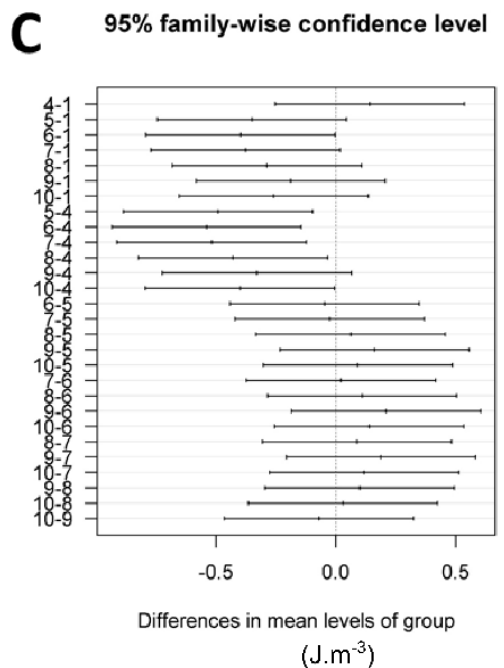

Figure S3. Visual representation of the results of Tukey multiple comparison analysis of the mechanical properties of the $\mathrm{CPC}$ formulations described here. A) Compressive modulus. B) Strength. C) Modulus of resilience. 


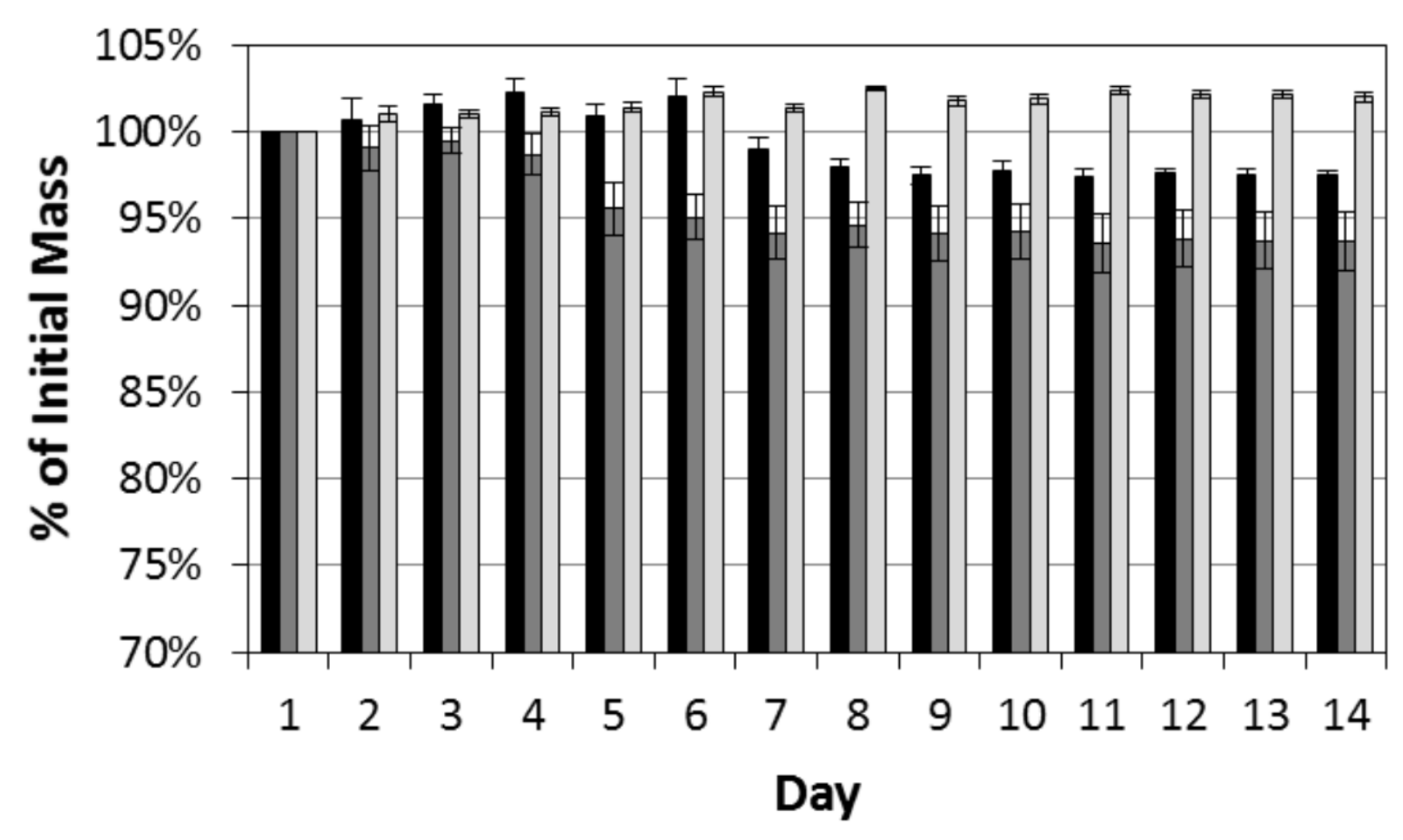

Figure S4. In Vitro Degradation Study. Black bars represent formulation 1. Dark grey bars represent formulation 5 with PGA sutures. Light grey bars represent formulation 8 with Monofyl® sutures. 